\title{
Investigating the Relationship of Economic, Social and Cultural Capitals with Fatalism in Isfahan
}

\author{
Kaveh Ehsani (corresponding author) \\ MA student of Social Science Research' Department of Sociology, Ashtian, Branch, \\ Islamic Azad University, Arak, Iran \\ Postal address: Fourth Floor, N.O 24, Mehr Street, Mohtagh2 Avenue, Isfahan Iran \\ E-mail: kavehehsani1 @gmail.com, Telephone: +98-9131094982 \\ Seyed Mahmoud Nejati Hosseini \\ Professor of Sociology, Department of Sociology, Islamic Azad University, Iran \\ E-mail: nejati.hosseini@gmail.com, Telephone: +98-9122045262
}

Doi:10.5296/ jsr.v6i2.8145 URL: http://dx.doi.org/10.5296/ jsr.v6i2.8145

\begin{abstract}
Evidence indicates that beliefs such as fortune and misfortune or how getting daily bread are typical theological fatalism in terms of Iranian religion and Islamic culture. On the one hand, although it seems that economic problems are the main factor associated with the fatalism in fatalistic nations, studies illustrate that Iranian society have suffered from mistrust, lack of social participation, knowledge and so on. Moreover, cultural crises have been embedded with their daily life nowadays. Consequently, the question is raised in the mind of the author that the fatalism might have a complicated relationship towards economic, social and cultural capital since the mistrust reduces participation and then the wheel of economic will be stopped. As a result, socio-economic and cultural capitals could have influence on the fatalism. The aim of this study is to investigate the fatalism of citizens in Isfahan according to the benefit of economic, cultural and social capitals. The theories of Marx's alienation and Durkheim's excessive discipline are used to study the fatalism. On the other hand, Bourdieu's perspective is used for studying the economic and cultural capitals as well as evaluating the social class and the lifestyle. The survey research has been conducted on the 300 residents of the city. A cluster sampling method is used in this study. The questionnaire is used as a data collection instrument and the Pearson Correlation Coefficient; t-test and ANOVA are used for the data analysis. Finally, it can be concluded that education, economic and cultural capitals and the lifestyle can influence on the fatalism more than other variables.
\end{abstract}

Keywords: Fatalism, Social Capital, Cultural Capital, Economical Capital, Lifestyle 


\section{Introduction and Statement of Problem}

People's beliefs about their own fortune and others' misfortune or how they are getting their daily bread are in the way that always their bread has been predetermined and really any attempts to change the conditions are useless. It is an indicator of the fatalism in the community. This is an example of such beliefs that are expanded in most societies. However, the fatalism is a social phenomenon and has rooted in the historical experiences and the political issues.

The sociologists know the sense of fatalism among the variables that result in hindering the adoption of a new culture and thus as a barrier to develop. Some authors like Graham Fuller believe that the Iranians on their lands had frequently faced with so many devastating attacks of close and far relatives and the tribes. Attacks that led to destroy and loot efforts and hard work create the material trappings of civilization such as the irrigation system and agriculture. This led to emerge gradually a cultural belief and faith in the vast upheavals of getting rich quickly and intense empowerment of the fate and assigning the "destiny" were considered to be an inseparable component of life. (Tohidfam, 2002: 38)

One of the great reflections of this phenomenon is to give up working and waiting to a determined destiny. As a result, hope for the future which requires the further efforts do not have a place on the Iranian intellectual structure. Moreover, Iranians have historically faced with this problem that after collapsing the authoritarian regime and a period of anarchy, a similar government has been in power. The long historical experience of understanding the fatalism and the absolutism led to the position they do not escape from the tyranny and the despotism that has a substantial impact on the nature of power. (Ghazimoradi, 1999: 180)

On the other hand, the rulers and government leaders announce the fatalism thinking of a person against God and His agent to strengthen and stabilize their position. In such a special structure, any person achieves a given understanding of the government and its position where no discretion will be there for him or herself and in a mixed process of objective as well as subjective conditions the individual's fatalism is promoted (Anvari, 1994: 49).

The results of previous researches about the fatalism indicates that the fatalism removes the burden of responsibility on the shoulders of a man and imposes a passive spirit to him and the human ability to impose a prominent and effective role pass away in the social life. Consequently, the question is raised in the mind of an author that the fatalism can influence on collective activities and social participation, now it is in the question that what relationship can be existed between social capitals and fatalism. Perhaps eliminating the idea from the social culture reduces the social isolation. Also they may strengthen the spirit of collaboration among people and increase their efforts to solve the problems and increase the deficiencies. Since Iranian lifestyle depends on the cultural and religious beliefs and convictions from the past to the present, this type of fatalism seems to be a cultural problem. Economic issues can also be effective in the fatalism because the evidence indicates that the poverty is associated with the fatalism of the people, and then the economic capital can have a relationship with fatalism. As a result, there is a relationship among social, economic and cultural capitals and their influence on each other. Then relationship between different types of capitals leads that 
the author examines the fatalism with the social, economic and cultural issues.

\section{Theoretical Framework}

\subsection{Fatalism and Social Order}

Durkheim has expressed a multidimensional view of the social order. This multidimensional approach makes us familiar with "pathology" of order which not only leads to the loss of order, but sometimes leads to the excessive discipline. Ultimately, resulting excessive discipline of Durkheim is a fatalistic view. For Durkheim, the suicide is associated with a religious structure which serves as the engine is running and shows the amount of contributions and affiliations of society members. Durkheim has argued the fatalistic suicide occurs when people will experience severe and fatal difficulties led to quite despair. Durkheim's concept of the suicide is used in opposite of anomic suicide (due to religious disbelief). The fatalism has changed into a general obligation in the person and facilitated the suicide in absolute despair moment. Steven Lukes considers Durkheim's anomy something like the self-alienation of Marx. Firstly, Durkheim attributes the relation of the individual to the socio-environmental factors and secondly as same as Marx's view he argues that a "social environment "is based on the predictable occupational divisions in the society. In other words, anomy due to the rapid growth of the market and major industry is common like the self-alienation. (Acevedo, 2003: 1-19)

Durkheim's discussion about the fatalism shows it as an anomie to refer a man's perception from the existing conditions. In his view, the fatalism is acceptance of the extreme legitimacy in which the future is desperately depictions of the dark position. Moreover, sensual feelings that are suppressed because of the unjust order are nothing but disappointment and frustration (Anvari, 1994: 111-113).

Extreme legitimacy is resulting from the rules and the beliefs leading excessive regulation, so that it ultimately leads to the anomies in the community and the suicide can be considered to be among these disorders. In a broader sense, the fatalistic suicide is a dissonance driven from the despair to change the current situation and accept any deprivation in the life. As an illustration, in the event of an accident failing to comply with the traffic rules and regulations, the weakness of these regulations or killing people in the incident are attributed to a predetermined event. Such an attitude is rooted in the order of extreme religious beliefs and convictions. As a result, such events indirectly indicate the fatalistic suicide, inasmuch as the failure to observe the basic traffic rules would be experienced again for the people who follow this excessive order. This means that they unwillingly commit the fatalistic suicide, because they do not have the power to change their attitudes and beliefs in order to excessive order of the wrong rules.

\subsection{Fatalism and Alienation}

In Marx's view, self-alienation as a result of economic relations of capitalism is not only a function of the extreme order, but also the consequences of economic and capitalism relations. The plan is according to Marx's clearer writings. The self-alienation is a significant point in the context of fatalism. Description of self-alienation is originated from the inequalities that 
have been inherited from the labor divisions. On the other hand, self- alienation is presented and described as the cognitive conditions of overall misery and desperation. Also it is a classic indicator of a person's fatalistic character. It has been noted that how Marx uses the word "slavery" that the possible use of the "slave" indicates an experimental prototype of people in community who believe in ultra-fatalism. Occupational divisions suggest a prototype of this fact that everyone has evolved naturally in society and continued their life. Therefore, when there is a voluntary activity, so naturally deeds of man will be a foreign power that puts in opposite of the man and rather than controlling draws him to the slavery. The occupations are classified according to the character of the individual; each person has a specific and unique nature for his or her activities. Marx added more details on topics and studied almost a fatalistic person on the basis of a form of alienation and the fatalistic belief. Marx criticized a fictional person who can work in any field and cooperate to produce the resources for community (with a social alien and possibly fatalistic character). In capitalism conditions he has participatory activity to produce the goods in this way and like it. These activities are not taken from an integrated internal power from the people, but also as an external force out of the person. So people have no ability to control themselves against the set of occasions and the steps that are independent of human wills and this action is the first conductor of the needs (Acevedo, 2003: 1-19).

Melvin Seeman is undoubtedly the first theorist who has tried to make a sense of alienation in a systematic and coherent frame and defined it. He points out to the expansion and development of the concept of contemporary society and believes that the alienation is a result of bureaucratic structure of a modern society. Because this structure has created a situation in which human cannot be able to do anything. The manner of controlling and managing the society is in the way that an individual is not able to connect his behavior and given rewards of society together. In such a situation the sense of alienation has prevailed on the individual and he will present an inactive and maladaptive action in the community. Seeman presents the concept of self-estrangement and tries to indicate five kinds of feeling and strange behavior:

- Powerlessness

- Meaninglessness

- Normlessness

- Isolation

- Self-estrangement

Then, according to the fatalism, just two conceptions of powerlessness and a sense of anomy are studied.

\subsection{1. 'Powerlessness'}

Feeling of powerlessness is the probability or imagined expectation by the individuals against the effects. In other words, his or her imagination to believe that a behavior is not determined to achieve the expected results and he is equipped by his actions did not lead to the purpose 
for which it is based. (Mohseni Tabrizi, 1991: 68) Feeling of powerlessness is in the opposite of the efficiency and the effectiveness. In socio-psychological point of view, powerlessness is a process of learning, because every one learns that any activity in this process is doomed to failure. If a person feels that his efforts in the field of social policy do not go anywhere, he will keep on trying again (Masoudnia, 2001, 157).

\subsection{2. 'Normlessness or Anomie'}

Durkheim's sense of anomie is that a man wandering and erratic against the rules and measures of social behavior. The concept of anomie is used in three separate means: First, the concept of a personal disorder that causes the confusion and lack of a rule and actualization for human behavior. Secondly, it refers to a social situation in which the rules of social behaviors conflict to each other and a person suffers the confusion to adopt these laws. Thirdly, it presents a social situation that there is a conflict between an individual and some social norms and behavior (Mohseni Tabrizi, 1994:135)

For Seeman, the feeling of normlessness is like powerlessness and meaninglessness of intellectual conditions in which a person supposes a possibility to limit excessive self and expects to achieve worthwhile goals required by illegitimate tools. This occurs when a person is convinced that only actions that are not approved by the community approach him to the objectives. The socio-political normlessness is along with devaluing political morality, and ignoring the standards of political conduct in order to achieve the stated objectives (Mohseni Tabrizi, 1996: 98).

Bureaucratic structure of a modern society is to form a sense of powerlessness, alienation and anomie. In other words, the individual role in transforming the society and achieving worthy goals finds only an inefficient and illegitimate means.

\section{Theories of Economic, Social and Cultural Capitals}

\subsection{Economic Capital and Formation of Social Class}

Regarding Marx's theory, the human in their existence makes the certain relationships that indicate a certain degree of developing productive forces of the material. A set of the economic foundations of society forms a real base of legal and political structure that occurs with certain forms of social consciousness. In general, the development of social, political and intellectual life is based on the mode of the material production. The consciousness of men determines their existence, unlike the human social existence that determines their consciousness. The process of assigning a man to establish the relations of production and the development of productive forces of the material causes to be away from their wills. This results in a difference in people's consciousness of their place in the production and the life (Tavassoli, 1998:86). Then, the result of this difference makes the level of "in-self" and "for-self" in people's knowledge.

Bourdieu believes that the principle of the Unitarianism class is the common character of its members. Character class distinctions create horizontal and vertical joints in social atmosphere. Every social class is defined on a combination of three types of capital: 
economic, social and cultural. Members of each class in their own right position are determined based on the combination of different types of capital. There is a mutual relationship and interaction between material conditions and manners. Therefore, for Bourdieu making the disparities through the production and reproduction of capitals are a source of economic capital and the formation of proper social class.

In other words, the benefit of the economic, cultural and social capitals causes to increase the consciousness and understanding of an individual's position in society. The impact of these types of capital on people's knowledge is a formative factor of social class.

\subsection{Social Capital and Social Cohesion}

Putnam's social capital is two basic forms of social capital connecting or "comprehensive" and the "intra-group" or "exclusive." Intra-group social capital is useful to strengthen specific interactions and transfer a correlation as well as a strong social connector to keep the strong intra-group loyalty and strengthen the identity of the specific actions. The connector provides a sociological insight for connecting external devices and facilities that can bring the broader identities and interactions. The theory of social capital of Putnam has certain similarities with the notions of Durkheim's solidarity (Field, 2008: 55-56).

As Bourdieu's explanation, the social capital is a type of individual or collective, conscious or unconscious investment that is seeking to establish or reproduce social relations that are directly usable in the short- or long-term. For him, durable and dense ties have a particular importance because of the level of individual social capital depending on the number and size of capital (cultural, social and economic) acquired by everyone (Field, 2003: 17). The size of social capital possessed by a person depends on the size of the network bonds in a way that he can effectively mobilize, and additionally is dependent on the capital size (economic, cultural or symbolic). Benefits of membership in a group make the cohesion to achieve the benefits in this way. The social capital is a means of access to economic and cultural resources through the social connections. Bourdieu's emphasis is on individual participation in social networks that the partnership would result in accessing to the group resource (Bourdieu, 2005).

Here everyone can find the negative aspects of social capital and be in the crossroads of the social solidarity and individual freedom. Social participation necessarily requires that the members do as same action as the congregation. In a small city or a village, all neighbors know each other. High level of social control in such spaces yet is in such a way that personal freedom is completely bound to the regulations. The same point is a reason that explains why young people and those who have an independent character always have left such environments. Compact multi-layer networks that tie people together are causing dense social life and strict enforcement of the local norms. In these places, individual freedom and independence in accordance with the present situation are less. That is why young people who are usually more independent leave the society (Alvani \& Shirvani, 2006: 87-86).

\subsection{Social Capital and Social Trust}

The starting point for Giddiness's the ontology is dialectic between activities and conditions 
that occur in a space and time. Trust depends on the foundation of time and place because the trust gives the commitment to the person, group or organization in the future. Trust is a modern idea. Risk and reliability are closely linked together. Trust to a person or a system, for example the banking system is a means of compliance with risk, but the risk can be a means of creating the trust (Giddiness, 2005:175-176). The evidence indicates that in traditional and fatalistic society people do low-risk levels or no risk at all. So a kind of distrust is seen to conditions and others in the community.

Coleman's rational choice theory made the main means of communication between the trusty person and the trusting one. This type of relationship is a form of action. That means that human beings are targeted in social actions to move for meeting their interests (Akhtar Mohagheghi, 2006: 59).

Therefore, social trust is one of the most important components of social capital. Due to the trust- social functions are laid in the rational choice. In other words, the extensive radius of trust is out of the limited and individual aspect, the collective and macro interests are created.

\subsection{Social Capital and Sense of Social Bonding}

In the view of many sociologists of structural-functional approach, a sense of belonging and social cohesion form the basis of social order and promote the unity and solidarity grounds. It causes to facilitate the confidence between massive populations. They believe that without a sense of social belonging among people, effective faith has not been achieved both knowingly and voluntarily. The more prevalent the sympathy, empathy and pace in society, the higher the community participation will be. A sense of belonging within the community is including a set of phenomena based on the opposition that can lead to make a mutually compatibility, therefore member becomes aware of their collective identity. The group through an active participation and achievement of everyone achieve a consensus (Biro, 2001:184).

Hirschi's social bond issue has been addressed in the document. Social control and social cohesion are key elements of social capital and social bonding theory of Hirsch. Hirsch believes four main elements which link an individual and society are including society's dependence, commitment, engagement (participation in social activities) and the belief to the social rules (Aliverdinia and Sharepour, 2008: 117).

\subsection{Cultural Capital and Social Class}

According to Bourdieu, a source of social and cultural capitals is education and family upbringing that naturally upper class has formal education and better culture or job in this regard and therefore this class has the more capital than others. (Fazeli, 2003: 47).

The concept of habit in Bourdieu's theory is a practice and expression of temper in social class. Bourdieu considers a social class to be affective on individual behavior, according to a grammar used for individual actions in the social field that becomes it far away from another. He uses a system to develop the plans and specific actions. "One particular habit has been emerged when it is indicated in the statistics in the way a range of variables (occupation, 
education, income, artistry and taste of food) is tied together" (Lechte, 1998: 81).

Bourdieu's theory of cultural capital that would result in the reproduction of the dominant class's culture is referring to the fact that the dominant classes have a more material and accessibility to different kinds of music, the sport, food and so on. They can shape their taste. In other words, Bourdieu considers every type of the details of the particular interests in the dominant or upper class to be a measure of cultural capital (Trasbi, 2003: 68-70).

Bourdieu acknowledges that the culture is directly involved in social inequality. This is especially seen around the concept of social class. For Bourdieu, classes, based on the total capital size (economic and cultural) are separated from each other and available for the individuals and the families.

\subsection{Cultural Capital and Lifestyle}

Bourdieu proposed a coherent theory of forming the lifestyles. According to his model, the objective conditions of life and the position of the individual in the social structure lead to the production of a specific manner and the character is divided into two categories including a system for classification of actions and another for perception and cognition (tastes). The end result of the interacting these systems are a lifestyle. The lifestyle is very practices and procedures specific to certain perceptions that are derived from the classifications. The lifestyle is also embodied in the form of individual preferences and visible actions. Non-random patterns characterize the class. Bourdieu shows the lifestyles are a product of manners and they are a function of the different experiences. For instance, the experience is a formal education and consumption patterns are the most important legacy of the lifestyle. He analyzes the relationship between the formal education in the capitalism structure and its reproduction. Bourdieu's concept of sociological analysis of consumption and lifestyles analyzes a variety of the resources to explain the consumption pattern and investigate the hypothesis of differentiating the levels of consumption and the cultural consumption (Fazeli, 2003).

\section{Research Review}

Most researches have been done on the social and psychological factors affecting the fatalism and investigated the relationship between economic, social and cultural capitals with fatalism, so here the paper refers to studies that have further investigated the fatalism itself.

A study, entitled "Social Factors Affecting Fatalism: a case study of Ferdos town" by Mohammad Rafiei (2003) examined the social factors underlying believing the fatalism among the residents. The survey and interviews were conducted with a sample size of 246 subjects. Among the results of this study, the relationship between religiosity of the students and the fatalism has been verified and it is found out that the greater the degree of religiosity among the students the further they will be subjected to the fatalism. Also, the result of a research indicated that there is an inverse relationship between the socioeconomic base and the students' fatalism. In other words, the higher the socio-economic base of students, the further the fatalism is falling among them. 
A research, entitled "The social classification, Mexican culture and fatalism, their effects on psychological distress" (1983) conducted by Katherine Rose, John Mirosky and William Cockerham clarified the causes and consequences of cultural fatalism. In this study, social and cultural factors have been investigated by a cognitive-perceptual direction and the effect of social class and culture of Mexico were examined on the psychological distress. The results of this study suggest that the theory of fatalism is considered to be a potential intermediate variable that explains the social class, cultural differences and their impact on the mental anxiety. Fatalistic ideas that can shape an action have the impact on the psychological distress. In other words, if a person believes that their efforts are useless and he cannot be effectively subjected to their community, he is helpless and incapable and then the person will play an inactive role in dealing with the problems. Lack of controlling over feelings leads to incompatible and inconsistent efforts with the goal and eventually results in psychological distress termination. Poor people are more fatalistic and fatalism in this regard increased their psychological distress. The results of this study indicate that people in lower social classes in Mexico, compared to those in upper ones are more fatalistic and it, in turn, increases the psychological anxiety (E.Ross, Mirowsky \& Cockerham: 1983).

Another study, entitled "Control context: the national survey of the relationship amongst social structure, fatalism and group activity" by Cochran, David Pettinicchio \& Young in 2010 was conducted to examine the effect of group activities focused on the fatalism. The result of this research suggests that the fatalism is a collective activity and reduces overall impact of political institutions in the country. In addition, the impacts of policy acquisition on collective action are generally subjected to the fatalism and the findings indicate the lack of adequate infrastructure, proper social and the psychological explanations of collective action (Corcoran, Pettinicchio \& Young: 2010).

Table1. Theoretical Research Summary

\begin{tabular}{|l|l|l|}
\hline Theorist & Key Concepts & Variables \\
\hline Durkheim, Marx & $\begin{array}{l}\text { Excessive regulation, fatalistic suicide, } \\
\text { limited social environment, self-alienation, } \\
\text { lack of human capacity to change the } \\
\text { events ahead }\end{array}$ & $\begin{array}{l}\text { Fatalism } \\
\text { dependent variable) }\end{array}$ \\
\hline $\begin{array}{l}\text { Putnam, Giddiness, } \\
\text { Durkheim, Seaman, } \\
\text { Coleman, Fukuyama }\end{array}$ & $\begin{array}{l}\text { Social networks, reciprocity norms, mutual } \\
\text { benefits, social trust, social actions, level of } \\
\text { extroverted social trust }\end{array}$ & $\begin{array}{l}\text { Social } \\
\text { (independent variable) }\end{array}$ \\
\hline $\begin{array}{l}\text { Durkheim, Putnam, or } \\
\text { Simmel }\end{array}$ & $\begin{array}{l}\text { Anomic suicide, connecting } \\
\text { "comprehensive" social capital , } \\
\text { intra-group "or small exclusive }\end{array}$ & $\begin{array}{l}\text { Solidarity } \\
\text { (independent variable) }\end{array}$ \\
\hline
\end{tabular}




\begin{tabular}{|l|l|l|}
\hline Hirsch & $\begin{array}{l}\text { Deviance, social control, family structure, } \\
\text { education, peer groups, participation in } \\
\text { social activity. }\end{array}$ & $\begin{array}{l}\text { Feeling of social bond } \\
\text { (belonging), } \\
\text { (independent variable) }\end{array}$ \\
\hline Bourdieu & $\begin{array}{l}\text { Field, habitus, cultural tastes, } \\
\text { subcategories, symbolic capital, creating } \\
\text { inequality in society, nature, lifestyle, } \\
\text { social class }\end{array}$ & $\begin{array}{l}\text { Education } \\
\text { (independent variable) }\end{array}$ \\
\hline Marx, Bourdieu & $\begin{array}{l}\text { Consciousness, "class in itself" class "class } \\
\text { for itself" class, habitus, cultural tastes }\end{array}$ & $\begin{array}{l}\text { Lifestyle (independent } \\
\text { variable) }\end{array}$ \\
\hline
\end{tabular}

According to the research done in the past with regard to the fatalism and theoretical framework among other theories of the fatalism, theories of Marx's alienation and Durkheim' excessive disciplines have placed in this study. On the other hand, among the theories of capital, to study the social capital theorists of social trust, social solidarity and social ties are used and Bourdieu's theory of social class and the theoretical framework of the research location have been used to evaluate the financial and cultural capitals and the lifestyle. The following table indicates the theoretical framework of the research.

The remarkable point about the table of theories is that to explain each variable, the names of theorists who have a theory about variable and all related concepts of theory have been mentioned. Meanwhile, the theoretical framework of the study has examined only the views of theorists that are more relevant to the main.

\section{Hypotheses}

1. It seems that there is a relationship between the social capital and the fatalism of the people in Isfahan.

- It seems that there is a relationship between the social trust and fatalism of the people in Isfahan.

- It seems that there is a relationship between the sense of social bond (belonging) and fatalism of the people in Isfahan.

- It seems that there is a relationship between the social cohesion and fatalism of the people in Isfahan.

2. It seems there is a relationship between the cultural capital and the fatalism of the people in Isfahan.

- It seems that there is a relationship between people's education and fatalism of the people in Isfahan.

- It seems that there is a relationship between the lifestyle of people and fatalism of the people in Isfahan. 
3. It seems that there is a relationship between the economic capital and the fatalism of the people in Isfahan.

- It seems that there is a relationship between the social class of people and fatalism in Isfahan.

\section{Research Method}

This study is a survey. Research population is the residents of Isfahan that according to census of 2006 their number is 1,624,838. A sample size of 384 subjects was determined by using the Cochran formula, but in practice, due to difficulties in conducting research including the time and cost constraints, finally, the sample size was reduced to 300 ones. A cluster sampling method was used in this study. After that the sample was allocated based on the percentage of the area, according to the socio-economic base, three of the areas were selected among them by this index based on the variables such as socio-economic status. Given the large population of these regions, the number of samples is selected from each region and is calculated based on the total number of samples $(n=300)$. The sample was including the number of 120 members from the lower region number 14 (40\%), 99 subjects from the medium zone number $4(33 \%)$ and 81 subjects from the upper region number 6 $(27 \%)$.

The data collection's tool was a questionnaire validated by the experts and proved its reliability with Cronbach's alpha that was calculated between 0.6 and 0.75 .

The unit of analysis in this study is an individual and in order to analyze the data the mean comparisons are used in addition to describe the statistics.

\section{Results}

This article is extracted from an original investigation; the results indicate that the data description is driven from 300 respondents including 162 (54\%) males and $138(46 \%)$ females participated in the study. Also the fatalism's mean between women and men is 34 and 32 , accordingly. It indicates that women are more fatalistic than men.

Also the 300 respondents, 67 subjects were aged 15 to 24 years, 87 subjects aged 25 to 34 years, 66 subjects aged 35 to 44 years, 51 subjects aged 45 to 54 years and 28 subjects in group are aged between 55 to 64 years. Overall, most respondents were aged 25 to 34 years. Average fatalistic people in the age group 15 to 24 years was 31, in the age group 25 to 34,32 ones, in the age 35 and 44 years, 33 ones, in the age group 45 to 54, 35 ones, in the age group 55 to 64 years, 36 subjects. These values indicated that older people's fatalism was greater than those younger.

Findings indicated that 3 out of 50 people are illiterate and 50 subjects had not a high school diploma and 128 ones had a diploma and 42 respondents had an associate degree, 70 persons had graduate degree and 7 ones had Master and $\mathrm{PhD}$ degree. In other words, 1 percent illiterate, 16.7 percent under diploma, 42.7 percent diploma, 14 percent associate degree, 23.3 percent graduate degree and 2.3 percent had Master and $\mathrm{PhD}$ degree. Average fatalism of the respondents was for illiterate, 34, under diploma, 37, diploma, 34, associate graduate, 32, 
undergraduate, 32 master and $\mathrm{PhD}, 28$. These figures indicate that the higher level of education among the respondents is, the lower their fatalistic view is.

To investigate the relationship between the dependent and independent variables, Pearson's Correlation Coefficient was used. In the table of correlation coefficient, the independent variables based on the highest level of correlations and the significance have been arranged from the top to bottom. Level of education is highly associated with the fatalism and a negative correlation direction indicates that the higher the education level is, the lower the fatalism is.

Table 2. Correlation coefficient between the independent variables and the dependent variable (fatalism)

\begin{tabular}{|c|c|c|c|c|}
\hline $\begin{array}{l}\text { Independent } \\
\text { variable }\end{array}$ & $\begin{array}{l}\text { Dependent } \\
\text { variable }\end{array}$ & Correlation & $\begin{array}{l}\text { Significant } \\
\text { level }\end{array}$ & Interpretation \\
\hline Family education & Fatalism & $(* *) 0.324$ & 0.000 & $\begin{array}{l}\text { There is a significant } \\
\text { relationship between two } \\
\text { variables. }\end{array}$ \\
\hline Age & Fatalism & (**) 0.297 & 0.000 & $\begin{array}{l}\text { There is a significant } \\
\text { relationship between two } \\
\text { variables. }\end{array}$ \\
\hline Economic capital & Fatalism & $(* *) 0.260$ & 0.000 & $\begin{array}{l}\text { There is a significant } \\
\text { relationship between two } \\
\text { variables. }\end{array}$ \\
\hline $\begin{array}{l}\text { Levels of social } \\
\text { trust }\end{array}$ & Fatalism & $(* *) 0.203$ & 0.000 & $\begin{array}{l}\text { There is a significant } \\
\text { relationship between two } \\
\text { variables. }\end{array}$ \\
\hline Cultural capital & Fatalism & $(* *) 0.175$ & 0.002 & $\begin{array}{l}\text { There is a significant } \\
\text { relationship between two } \\
\text { variables. }\end{array}$ \\
\hline Social capital & Fatalism & $(* *) 0.155$ & 0.007 & $\begin{array}{l}\text { There is a significant } \\
\text { relationship between two } \\
\text { variables. }\end{array}$ \\
\hline Lifestyle & Fatalism & (*) 0.125 & 0.031 & $\begin{array}{l}\text { There is a significant } \\
\text { relationship between two } \\
\text { variables. }\end{array}$ \\
\hline
\end{tabular}




\begin{tabular}{|l|l|l|l|l|}
\hline $\begin{array}{l}\text { Independent } \\
\text { variable }\end{array}$ & $\begin{array}{l}\text { Dependent } \\
\text { variable }\end{array}$ & Correlation & $\begin{array}{l}\text { Significant } \\
\text { level }\end{array}$ & Interpretation \\
\hline Social Solidarity & Fatalism & $(*) 0.117$ & 0.044 & $\begin{array}{l}\text { There is a significant } \\
\text { relationship between two } \\
\text { variables. }\end{array}$ \\
\hline $\begin{array}{l}\text { Feeling of social } \\
\text { bonding } \\
\text { (belonging) }\end{array}$ & Fatalism & 0.048 & 0.409 & $\begin{array}{l}\text { There is no significant } \\
\text { relationship between two } \\
\text { variables. }\end{array}$ \\
\hline
\end{tabular}

(**)Correlation is significant at the 0.01 level. level.

(*) Correlation is significant at the 0.05

\subsection{Test of the Relationship between the Gender and Fatalism:}

Explained results of the relationship between two variables were performed through a statistical comparison and also the t-test analysis was used. In the following table, F-test and Homogeneity of Variance Tests did not indicate the significant differences between the variances $(\mathrm{sig}=0.274)$. T-test results indicated that the differences between men and women in terms of the fatalism are not statistically significant.

Table 3. T-Test to investigate the sex and fatalism

Examining the relationship between the gender (independent variable) and fatalism (the dependent variable)

\begin{tabular}{|l|l|l|l|l|}
\hline & \multicolumn{2}{|l|}{ Checking out mean } & \multicolumn{3}{l|}{ Equality of variance } \\
\hline Test type & $\begin{array}{l}\text { Significant level of both } \\
\text { domains }\end{array}$ & F-value Sig & Interpretation \\
\hline T-test & 0.001 & 1.199 & 0.247 & $\begin{array}{l}\text { The difference was not } \\
\text { significant. }\end{array}$ \\
\hline
\end{tabular}

7.2. Testing the relationship between social class and the fatalism

Explaining the relationship between two variables above was compared by using the ANOVA test. The table below does not indicate a significant difference between the variances. The test results indicate that there is no a significant difference among upper, middle and lower classes and fatalism. 
Table 4. ANOVA test for investigating social class and fatalism

\begin{tabular}{|l|l|l|l|}
\hline Test type & F Value & Sig & Interpretation \\
\hline ANOVA & 0.771 & 0.464 & The difference was not significant. \\
\hline
\end{tabular}

\section{Discussion and Conclusion}

Given the findings it can be mentioned as a general conclusion that the fatalism can be an effective factor on the social activities of society members, because the belief in the destiny grows up individually and indicates their effects in the community. People who do pay little attention to the fate of the society and its role in their lives consider it to be an integral part of their life, so all the events and problems are plaguing them and they do not attempt to improve the situation and solve their assaulting problems and attribute them to their destiny. Belief in the fatalism has be originated from the far past and has formed in the minds of Iranians. Given the overall research findings, fatalistic people in Iran are theosophical fatalist in the term of absolute knowledge of God. In this research, it was sought to survey and analyze the fatalism in the view of economic, social and cultural capitals and finally it is important to see how these variables affect the fatalism. The results of the study are summarized in the following expressions.

The hypothesis examined the relationship between fatalism and economic capital and it was confirmed. Thus, the fatalism is under the influence of the economic capital.

The hypothesis examined the relationship between fatalism and education and it was confirmed. Thus, the fatalism is under the influence of the education.

The hypothesis examined the relationship between fatalism and lifestyle and it was confirmed. Thus, the fatalism is under the influence of the lifestyle.

The hypothesis examined the relationship between fatalism and cultural capital (including education and lifestyle) and was confirmed. Thus, the fatalism is under the influence of cultural capital.

Some previous researches pointed out the relationship among social and economic status and the fatalism (Rafiei, 2003) and others have pointed out the relationship between social class and the fatalism (Rose, Mirosky and Cockerham, 1984). Since the economic and cultural capitals are key indicators of social class and in this study, the relationship between them and fatalism has been approved. Although it can be expected that the relationship between social class and the fatalism is confirmed, the results indicate that there is no a significant difference between upper, middle and lower class and the fatalism. According to the author's idea, this disapproval is supposed because of different but intense religious and cultural beliefs among all social classes and Iranian culture.

As regards in this study, social capital and the fatalism have a controversial relationship to each other, but for the author, the social capital allows the community to trust and cooperate with each other. Therefore, it should be provided by the health communicative network 
between members as well as removing the existing distrust by the active partnership. Furthermore, the solidarity with the confidence contributes to create a unified society and generally it intensifies the collective interest than the individual. In this case a collective success is achieved when the individuals make a satisfactory result and therefore they consider their role to change the individual and collective fate. Regarding the meaningful relationship between social trust and fatalism, a considerable point to describe the relationship is an inverse relationship but the author thinks a positive relationship between existing the fatalistic thinking formed from a kind of religious faith. As a result, somehow these beliefs lead to unify such Muslims' community. Therefore, more detailed research could be useful in this field. On the other side, deteriorating economic conditions and economic instability have caused the problems throughout the life of the individual and society that will have a negative impact on the network of social relationships and ultimately will hurt cultural issues. Therefore, creating a stable economy seems an essential measure for the public; thus government policies are effective.

Finally, according to the findings, the main objective of changing the attitude of fatalism is to create a belief that every human can alter his destiny and the community can increase the consciousness of the people. The most important factor for creating this consciousness is a capacity to build the reception of consciousness. In other words, a society that has pretty passion on religious beliefs and their history shows the submission to the events. In fact, they fear to seek and understand the facts. The author suggests that the effect of cultural, social and economic capitals on knowledge of people can make the capacity required to accept the effective knowledge.

\section{References}

Book

Akhtar Mohagheghi, M. (2006). Social capital. Tehran: Tehran Publications

Alvani, M. and Shirvani, A. (2006). Social capital. Tehran: Mani Publications

Bier, A., \& Sarookhani B. (2001). Encyclopedia of the social sciences. Tehran: Keyhan Publications

Bourdieu, P. (2005). Capital forms. Afshin Khakbaz and Hussein Pooyan, Tehran: Shirazeh Publication

Fazel, M. (2003). Consumption and lifestyle. Qom: Sobh-e-Sadegh Press

Field, J. (1998). Social capital. Translated by Ghaffari Gh. and Ramezani, Tehran: Kavir Publications

Ghazimoradi, H. (2001). Self-oriented Iran. Tehran: Akhtaran Ketab

Giddiness, A. (2005). The consequences of modernity. Translated by M. Salasi, Tehran: Markaz Publication

Lechte, J. (2008). Fifty contemporary thinkers: from structuralism to post-modernity. 


\section{Macrothink}

Translated by Mohsen Hakimi, Tehran: Khojasteh Publications

Tavassoli, Gh. (1998). Theories of sociology. Tehran: Samt Publications

Trasbi, D. (2003). Economics and Culture, K. Farhadi, Tehran: Ney Press

Tohidfam, M. (2001). Barriers to cultural development in Iran. Tehran: Center of Iran and the Islamic recognition (Baz Publications)

Paper and Thesis

Aliverdinia, A. Sharepour, Mahmoud and Varmarzyar, M. (2008). "Social capital and crime families". Women's Research 2:132-107.

Anvari, H. (1994). Research on fatalism. MS Thesis, University of Allameh Tabatabaiei

Masoudnia, E. (2001). Sociological explanation of disinterestedness among the citizens in social and political life. Journal of Political Economy 152, 165,167 \& 168.

Mohseni Tabrizi, A. (1991). The concept of alienation and grouping theories in the field of Sociology and Psychology. A social science letter, 2: 69-67.

Mohseni Tabrizi, A. (1994). Thoughts about committing the suicide taken from Durkheim's theory, a social science letter. 7: 136-135.

Rafiei, M. (2003). Social factors affecting fatalism. MA Thesis, Tarbiat Modarres University

English Sources

Acevedo, Gabriel .(2003). On Durkheim's Fatalism: The Hidden Link between Anomie and Alienation." Paper presented at the annual meeting of the American Sociological Association, Atlanta Hilton Hotel, and Atlanta, GA

Corcoran K., Pettinicchio D. \& Young J. (2010). The Context of Control: A Cross-National Investigation of the Link between Social Structure, Fatalism, and Collective Action.” Revise and resubmit British Journal of Social Psychology.

E.Ross, C. \& Mirowsky, J. and C.Cockerham, W. (1983). Social Class, Mexican culture, and fatalism: Their effects on psychological Distress. American Journal of Community Psychology, vol. 11, No. 4.

Seeman M. On the meaning of alienation. Amer. Social University of California, Los Angeles, CA. Rev. 24:783-91. 